R. J. Cohen and W. T. Sullivan, III, eds.

\title{
The Situation of Light Pollution in Germany
}

\author{
Andreas Hänel \\ Museum am Schölerberg, Am Schölerberg 8, D-49082 Osnabrück and \\ DARK SKY, working group of the Vereinigung der Sternfreunde e.V., \\ Germany. \\ email: ahaenel@rz.uni-osnabrueck.de
}

\begin{abstract}
The central European climate in Germany is not ideal for serious astronomical observations. Increasing light pollution hampers thousands of amateur astronomers and millions of people from seeing starry skies and the Milky Way.

To study the sources of light pollution, we estimate the increase of light pollution in Osnabrück, a town of about 160,000 inhabitants located in northwestern Germany. We try to extrapolate these statistical data to Germany and discuss possible reasons for increasing light pollution though the energy consumption stagnates. Some enthusiasts of the German amateur association "Vereinigung der Sternfreunde" have formed a working group DARK SKY to exchange information on this matter. Finally, we present some activities to make the public aware of the problem.
\end{abstract}

\section{Introduction}

Weather conditions in Germany are not favorable for astronomical observations. Therefore astronomers at traditional observatories such as Hamburg, Potsdam, Göttingen, Bonn, Jena, Heidelberg or München concentrate most of their research at observatories in better climates. Yet thousands of amateurs must stay home and struggle against light pollution. Therefore they build small observatories outside of the cities, take their transportable telescopes to one of the rare dark places in Germany or travel to remote foreign places like Gornergrat, Haute Provence, Pico Veleta, or Namibia.

Millions of people have a latent interest in astronomy, but they have only rare chances to see the wonders of the starry sky because the sky is heavily light polluted. Coming to a planetarium they are fascinated by the projection technique and by the artificial dark sky. Many visitors see the Milky Way for the first time in the planetarium.

\section{Estimating Light Pollution in Germany}

Shocked by the predictions for the increase of sky brightness published by Sullivan (1984) and Riegel (1973) for the United States, we wanted to estimate this increase for Germany. No continuous measurements of sky brightness at German observatories are known. Instead, limiting magnitudes determined by 
an amateur observer of variable stars in Stuttgart can be used to estimate the increase of light pollution: in 1958 the limiting magnitude was $5.6 \mathrm{mag}$, in 1971 it increased to $5.2 \mathrm{mag}$ and since then it has increased by about $0.1-0.2 \mathrm{mag}$ (Marx 1972, 1997, priv. comm.).

The main contributors to light pollution are:

- Lights for advertising. These seem to play a minor role in Germany, because they are restricted for traffic safety reasons. Increasingly disturbing become the powerful moving spotlights used by entertainment establishments such as cinemas or discotheques. In rural areas these skybeams are visible over dozens of kilometers and they increase the brightness of the night sky considerably. Due to different judisdiction in the cities, many still shine, but some have been switched off, for traffic safety or environmental reasons.

- Direct and indirect lights from industry and private households, such as illuminated windows, or unshielded garden lighting or security lights. Their contribution is difficult to estimate.

- Street lighting is the most important contributor, though estimates in the literature vary between $14 \%$ (cited by Schreuder 1991) to $50 \%$ (Shaflik. 1997), a value that seems more realistic.

As no data on increasing light pollution exist, we will estimate this from the increase of electric power consumption. Detailed information on energy consumption for street lighting in Germany exists for 1989 , when $2.810^{9} \mathrm{kWh}$ were used in the (former) western Länder in Germany, while the total consumption of electricity was $3.910^{11} \mathrm{kWh}$. In 1996 the energy for street lighting had risen to $3.510^{9} \mathrm{kWh}$ for the reunified Germany, while the total power consumption was $4.810^{11} \mathrm{kWh}$ (Bundesministerium für Wirtschaft 1996). From these data for Osnabrück and Germany it can be estimated that less than $1 \%$ of the total electric energy is used for street lighting.

Detailed figures about street lighting in Osnabrück, a city with 160,000 inhabitants in northwestern Germany, are available since 1981, as provided by the Stadtwerke Osnabrück, the municipal energy supplier (private communication). Eigure 1 shows the percentage increase for the number of luminaires, the power consumption and the power supply. While power supply and consumption remained more or less constant, the increase of the number of luminaires is remarkable. The main reason for this is the increasing number of residential areas where lighting has to been installed by the Stadtwerke. Power supply and consumption have remained constant for different reasons:

- Financial cuts in the public administration force the reduction of energy costs. Therefore street lights are reduced or even switched off at certain times (after $11 \mathrm{pm}$ or midnight).

- More efficient lamps are used. In residential areas there is an increasing trend to compact fluorescent lamps or high-pressure sodium lamps. On main streets mercury vapour lamps are replaced mainly by high-pressure sodium lamps, sometimes by low-pressure sodium lamps. However, due to 


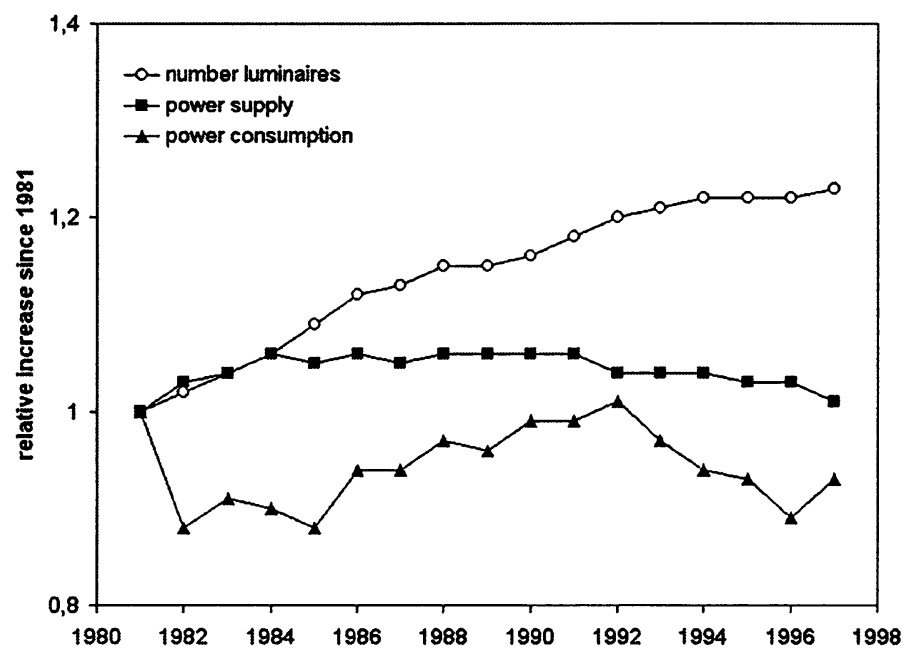

Figure 1. Percentage increase of number of luminaires, power consumption and power for public street lighting in Osnabrück.

their monochromatic colour the low-pressure sodium lamps are not very much favoured.

Figure 2 shows the relative increase of electric power consumption in Osnabrück, Germany and the United States since 1950. We assume that the power consumption for light amounts to about $1 \%$ of the total power consumption in Germany during the whole time interval. In addition, the light emitted towards the sky depends on the efficiency of the lamps, their shielding and the reflectivity of the streets. The increasing light emission postulated by Riegel (1973) is due to the fact that the number ratio of vapour/incandescent lamps increased from 0.1 in 1960 to 1.2 in 1970. In Germany incandescent lamps have rarely been used. Besides mercury vapour lamps, fluorescent lamps have often been used. We assume that the light efficiency of the lamps has increased from a mean of $40 \mathrm{~lm} / \mathrm{W}$ (corresponding to $50 \%$ fluorescent, $40 \%$ mercury vapour, $10 \%$ incandescent lamps) to $100 \mathrm{~lm} / \mathrm{W}$ (50\% fluorescent, $25 \%$ mercury vapour, $25 \%$ sodium vapour) during the time interval considered. We then find the relative light increase for Germany given in Fig. 2. Therefore we suspect that the increase of light emission in Germany and perhaps in all Europe is not as high as estimated by Riegel (1973) for the USA.

In Germany street lighting is regulated by the Deutsche Industrie-Norm DIN 5044 which recommends on principal roads a minimal luminance between 0.3 and $2 \mathrm{~cd} / \mathrm{m}^{2}$, depending mainly on traffic density. Later at night, when the traffic density is less, illumination should be reduced. On the other hand there exist guidelines (Messung und Beurteilung von Lichtimmissionen, Länderausschuss für Immissionsschutz) for light emissions that indicate that vertical illuminance values of more than $1 \mathrm{~cd} / \mathrm{m}^{2}$ may already be considered as annoying. 


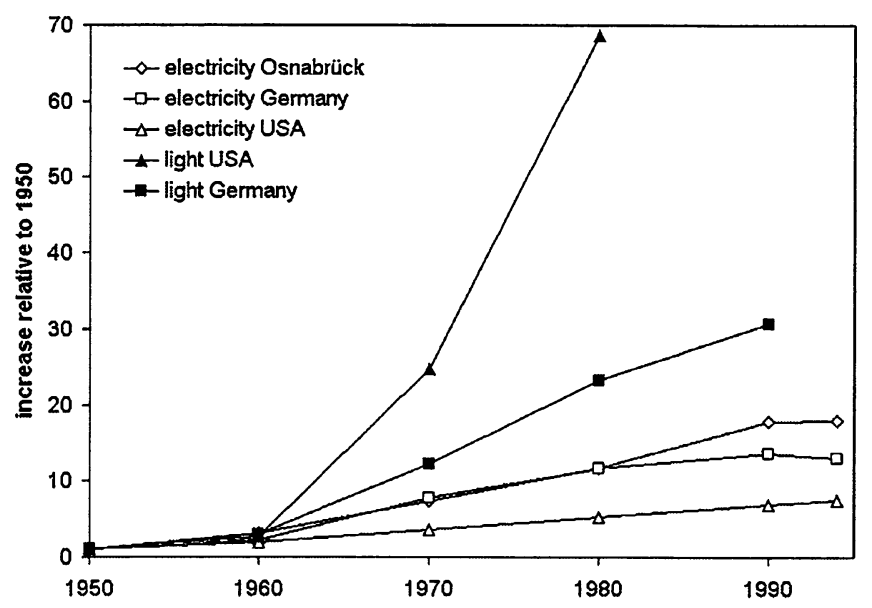

Figure 2. Percentage increase of power consumption and increase of light pollution in Osnabrück, Germany and the United States.

\section{Aims for Reducing Light Pollution}

Altogether, the following energetic and social factors influence the future increase of light:

- Light emission will increase due to:

- more lamps with the extension of new residential or industrial areas

- more efficient lamps

- increasing demand for more security

- decreasing costs for electricity (due to the liberation of the European market for electricity)

- new lighting norms planned by the European Community, which seem to be less stringent than the national norms.

- The following reasons might produce a stagnation of lighting increase:

- financial cuts at the public sectors

- less stray light from more efficient fixtures

- aims to reduce $\mathrm{CO}_{2}$ production in the framework of a sustainable development (agenda item 21 from the UN conference in Rio de Janeiro)

- introduction of ecological taxes, as planned in Germany

- increasing public awareness of light pollution as energy waste, annoying light emission, and having negative influences, for example on nocturnal animals. 
We think that one important step to reduce light pollution is to inform the public. Therefore in 1993 we started in Osnabrück with a poster presentation at a local fair on ecology, giving some information on the theme.

In 1995 some members of the association of amateur astronomers Vereinigung der Sternfreunde ( $V d S$ ) formed a group called "DARK SKY" to exchange information on problems and possible solutions of light pollution. This group meets once per year on the occasion of the international telescope meeting at the Vogelsberg in the centre of Germany, which is one of the rare dark places. At the last meeting some biologists participated, because nocturnal insects and birds are disturbed by overwhelming night lighting. In a study by the Naturschutzbund NABU (Schanowski and Späth 1994), insects were collected at different sorts of lamps. It was shown that many fewer insects are attracted by sodium vapour lamps than by compact fluorescent or mercury lamps due to less ultraviolet emission. The group DARK SKY also issues press releases and information sheets. Main communication is via email and the general public can get more detailed information from our web site :

http://www.physik.uni-osnabrueck.de/astro/

In 1996 we proposed an experiment for the Astronomy On-line project of the European Southern Observatory (ESO) in collaboration with the European Association for Astronomy Education (EAAE). The aim of this project was to demonstrate the use and the advantages of the internet to young people (West and Madsen 1997). We proposed to measure light pollution in Europe by using the simple method of determining the limiting magnitude in the constellation Ursa Minor. However, during the peak phase of this project in November 1996 , weather conditions were extremely bad, and only 25 reports were received, mainly from the southern parts of the continent.

Finally, a planetarium is another medium where light pollution can impressively be demonstrated to the public, just by raising the dome illumination a little bit. The worsening visibility of faint stars, the Milky Way, or a comet's tail is then dramatically demonstrated.

Acknowledgments. I would like to thank the Stadtwerke Osnabrück for providing the data for Osnabrück.

\section{References}

Bundesministerium für Wirtschaft 1996, Energie Daten '96 (and earlier years) Marx, H. 1972, in 50 Jahre Volkssternwarte Stuttgart, Verein Schwäbische Sternwarte ed., p. 41.

Riegel, K. 1973, Science, 179, 1285

Schanowski, A., Späth, V., 1994, Überbelichtet, Naturschutzbund Deutschland (NABU), Kornwestheim.

Schreuder, D. 1991, in Light Pollution, Radio Interference, and Space Debris, D.L. Crawford ed., Astr. Soc. Pac. Conf. Ser. 17, p. 25

Shaflik, C. 1997, Inform. Sheet 125, International Dark-Sky Association, Tucson

Sullivan, W. 1984, S\&T, 67, 412

West, R., Madsen, C. 1997, The Messenger, 87, 51 